\title{
Imprisonment for South Ethiopian people living with HIV presents a double health burden: exploring the barriers and facilitators of optimal HIV care
}

Terefe Gone Fuge ( $\nabla$ terefegone@gmail.com )

Flinders University

George Tsourtos

Flinders University

Emma R Miller

Flinders University

\section{Research Article}

Keywords: Imprisonment, antiretroviral therapy, adherence, barriers, facilitators, South Ethiopia

Posted Date: November 19th, 2021

DOl: https://doi.org/10.21203/rs.3.rs-1095569/v1

License: (c) (i) This work is licensed under a Creative Commons Attribution 4.0 International License.

Read Full License 


\section{Abstract \\ Background}

Optimal adherence to antiretroviral therapy (ART) is crucial for ensuring treatment benefits as well as prevention of further transmission. However, whilst the prevalence of ART non-adherence in prison populations is considered to be high in many countries, little information is available about its predisposing circumstances in resource limited countries. We explored the barriers to and facilitators of ART adherence amongst inmates living with HIV (ILWHA) in South Ethiopia with the aim of contextualising this significant public health problem and to make advances towards optimal HIV care.

\section{Methods}

We conducted qualitative in-depth interviewing with eleven ILWHA (eight male and three female ILWHA) and eleven service providers (seven male and four female service providers). Audio recorded interview data were transcribed verbatim in Amharic language, translated into English and coded based on emerging themes. A phenomenological approach was employed to abstract meaning attributed to the prisoners' lived experiences in relation to ART adherence and service providers' experiential account regarding HIV care provision.

\section{Findings:}

Several themes emerged in relation to barriers of ART adherence amongst ILWHA in South Ethiopia: limited access to standard HIV care, insufficient health staff support, uncooperative security system, loss of patient privacy, a lack of status disclosure due to social stigma, depression related to imprisonment and food supply insufficiency appeared to negatively influence adherence. In addition to a unique opportunity offered by an imprisonment for some ILWHA to refrain from health damaging behaviours, the presence of social support in the prison system facilitated ART adherence.

\section{Conclusions}

This study identified important structural, social and behavioural factors that can both hinder and enhance ART adherence amongst ILWHA in South Ethiopia. Given the high prevalence of HIV infection in prisoners and the potential of transmission to others during and after incarceration, policy and practice development is required to address the barriers to ART adherence and to also strengthen the enablers with regard to an asset-based approach.

\section{Introduction}


Optimum antiretroviral therapy (ART) adherence ( $\geq 95 \%)$ is essential to achieve viral suppression, increase survival rates in people living with HIV (PLWHA), and to prevent community transmission [1-3]. Non-adherence can cause drug-resistance (treatment ineffectiveness) which leads to increased use of costly second line drugs [4-6]. Prisoners are defined by the World Health Organization as a 'key' population that bears a disproportionate burden of HIV infection relative to the general population and has a higher potential of transmitting to others during and after incarceration [3, 7]. The burden is much higher in prison populations that are associated with resource limited countries $[7,8]$. The prevalence of ART non-adherence for inmates living with HIV (ILWHA) is considerably higher in many countries. A systematic review of studies in eleven different countries [9] reported a pooled non-adherence prevalence of $45 \%$. Other individual studies also reported a higher prevalence ranging from $55-58 \%$ in Spain $[10,11]$ and from $11-38 \%$ in the USA $[12,13]$. A study in Greece [14] identified ART non-adherence for $56 \%$ of ILWHA.

Various structural, psychosocial, behavioural and sociodemographic characteristics have been reported as contributors to suboptimal ART adherence in ILWHA. Amongst structural barriers reported, protracted processes involved in accessing care [15-18], unplanned transfers between correctional facilities [17, 19] and poor HIV care provider support $[13,17,18,20]$ crucially affected ART adherence. Psychosocial factors such as a lack of social support [9-11, 13, 21, 22], stigma related to loss of privacy $[15,17,18,23]$ and being medically diagnosed with a psychiatric disorder $[9,10,18,22,24]$ have been associated with ART non-adherence in ILWHA.

The likelihood of adherence is low in ILWHA who experience more frequent antiretroviral (ARV) sideeffects $[10,18-21]$ and other underlying health conditions[11, 18], and in those who have a history of injecting drug use (IDU) $[9,11,18]$. ILWHA who adopt negative perceptions of the safety and efficacy of ART $[10,11,24]$ and those who have low awareness of its health benefits $[14,18,23]$ are also less likely to be adherent. Moreover, higher odds of non-adherence have been reported in inmates in younger age groups (below 40 years) relative to older inmates $[9,14]$.

The level of ART adherence amongst ILWHA in resource limited countries is yet to be determined, and there is only limited information available regarding contextual barriers. The authors from the available studies have reported an absence of standard HIV care in prison systems and associated barriers to adherence including a lack of transport to ART clinics external to prison [23, 25, 26], as well as a food supply insufficiency $[20,23,26]$. These studies, however, were limited in their focus on exploring the influences of psychosocial and behavioural aspects. No investigations have been undertaken in Ethiopia to understand contextual factors that may affect ART adherence in this key population. Therefore, we undertook a qualitative exploration of barriers to and facilitators of ART adherence amongst ILWHA in South Ethiopia; one of the regions in the country with a steady HIV prevalence over the last decade despite a steep decline at national level, attributed to its majorly rural communities [27] from where prisoners often originate [28].

\section{Methods}


A detailed description of our methods is provided in an earlier report [29]. In summary, we conducted indepth, semi-structured qualitative interviews in four selected prisons (Hossana, Wolayta, Wolkite and Worabe prisons) in South Ethiopia and in the respective external ART clinics that were providing ART services for ILWHA in the four prisons. Eight male and three female ILWHA were interviewed, as were eleven service providers (seven male and four female service providers). Among the service providers interviewed were: two prison health care staff, three ART service providers, two prison officers, two prison administrators and two health agents (details provided below).

Prisoner participants who were 18 years or older were selected purposively based on their experience of incarceration and ART use of at least six months. Service provider participants were selected based on their role in HIV care provision for prisoners. The prison health care staff interviewees were engaged in providing routine medical care for prisoners, whereas ART service providers were health professionals who were providing ART services for both incarcerated and non-incarcerated PLWHA at the selected public health care facilities. The prison officers were involved in accompanying ILWHA to external ART clinics to access care. The prison officials interviewed were members of the administrative bodies of correctional facilities who provided HIV care, whereas the health agents were representatives of the respective Zonal Health Departments who technically support the prison healthcare system. All staff participants had more than six months of experience in their respective positions (see results section). The sample size for both groups was determined based on data saturation [30].

\section{Data collection}

The principal researcher (TGF) conducted the interviews using an interview guide constructed with openended contextual questions. While the interview guide for prisoners focused on structural, social and behavioural barriers to and facilitators of optimal adherence to ART, the service providers were asked for their experiential account of the existing HIV care provision and support strategies. The interview guide was piloted with people from the targeted population at institutions other than the study sites. The interviews were undertaken in Amharic language, a widely spoken language across Ethiopia and in the study area. The prisoner's ability to fluently speak the language was therefore considered during the selection process to ensure verbal fluency and clarity of ideas to the interviewer.

Prisoner interviews (45-60 minutes) were carried out in the prison health clinic. Service provider interviews (40-50 minutes) were conducted in the participants' private offices. The interviews were audio recorded and field notes were made on tacit knowledge [31, 32]. The audio recorded data were first transcribed verbatim in Amharic language and then translated into English for analysis.

\section{Analysis}

We used a phenomenological approach to analyse the interview data [33, 34]. Data were first understood by repeated readings of the transcripts and reviewing of field notes. Descriptions representing particular 
phenomena, as Giorgi [33] (on page 5) said these 'meaning units', were then detected whenever there was a transition in meaning in the description. The principal researcher (TGF) initially coded and recoded the meaning units to check if there was any intrapersonal inconsistencies in the coding process. Final themes were decided after triangulating different interpretations and reaching a consensus between the researchers (TGF, GT and ERM) through subsequent discussions and review of the themes. NVivo12 qualitative data analysis software [35] was used to code and juxtapose the themes in a chronological order of events and conceptual relationships. Data were interpreted by comparing supporting and opposing concepts within and between transcripts and with theoretical concepts in terms of recurrence, patterns and relationships $[31,34,36]$.

\section{Ethical approval}

The Flinders University Social and Behavioural Research Ethics Committee (SBREC) (Project Number: 8362) and Ethical Review Board of Southern Nations, Nationalities and People's Regional (SNNPR) Health Bureau granted ethical approval for the study procedures. Formal permissions were received from the SNNPR State Prison Administration and Regional Health Bureau (RHB), and from each correctional and health care facility authority. Written consent was obtained from all study participants to confirm voluntary participation.

\section{Results}

\section{Participant characteristics}

Full details of the participant characteristics have been described in an earlier report [29]. In summary, prisoner participants had a median age of 35 years. Seven inmates had been incarcerated for more than one year, six were diagnosed with HIV during incarceration, and five were initiated on ART in prison. Seven prisoners reported five or more years' experience of living with HIV and five had used ART for five or more years. All prison health care staff and ART service providers had a tertiary qualification in health related disciplines and more than six months' experience in their respective positions. Prison officer participants had two or more years' experience of facilitating ILWHA's accessing of care from external ART clinics. Prison and health administrator participants had been managing and providing technical and material support for the prison healthcare system for four or more years.

The following section presents themes that emerged as barriers to and facilitators of ART adherence amongst ILWHA in South Ethiopia. Under each identified theme are selected quotes that exemplify the reflections of most participants. Pseudonyms are used instead of real names of individuals mentioned in the interviews and letters to represent the prisons, health care facilities as well as health departments in order to prevent potential identification of persons providing the information.

\section{Barriers to ART adherence}

\section{Limited access to HIV care}


The prison system in South Ethiopia was marked by a lack of standard HIV care which imposed additional 'suffering' on ILWHA and represented a 'double burden'; the imprisonment itself and inappropriately treated HIV infection. The perception of many of the inmates' was that both HIV infection and incarceration occurred incidentally but were highly likely to produce psychological as well as physical trauma. One prisoner who used ART in prison for four years explained how difficult it was for ILWHA to cope with both conditions in a context where there was sub-optimal HIV care:

"Most [HIV infected] people suffer here because of lack of support, they are embarrassed by imprisonment on one hand and by the disease on the other hand. People here also cause embarrassment to us; better be hurt physically rather than having a psychological trauma. ---there are people who are severely hurt both physically and mentally." (38 years old, male prisoner; Prison 'B').

Another inmate being treated with ART in prison for approximately eight months proposed that incarceration alone represents a burden to all prisoners, but a lack of HIV care in a prison system exacerbates the burden to ILWHA:

"--No human being is free from incidents; I came here incidentally. Both a crime and disease are incidents. Everyone comes here whenever he commits a crime but he should not suffer from a double burden." (38 years old, male prisoner; Prison 'C').

Although ILWHA who had been using ART before incarceration indicated an intention to adhere to the therapy after being arrested, absence of HIV care in the prison system caused substantial delays in treatment continuation.

"I thought I had enough in my bag [during arrest] but it was empty. Then I let them [prison health staff] know about the issue but there is no HIV treatment service here. Thus, the only chance I had was calling my family to bring me some if there was any... But I ignored that because they [prison security] didn't allow me to do so." (32 years old, male prisoner; Prison ' $C$ ').

In all prison settings, ILWHA were accessing ART services from external health care facilities, which presented a series of intra-institutional and inter-institutional barriers to adherence. At some settings, access to care was adversely influenced by the long distance between a prison and an ART site, as there was no facilitation of transport by the prison system.

"It [referring to an external ART site] is too far to go on foot. Sometimes it feels demotivating because of the exhausting journey." (45 years old, female prisoner; Prison 'A').

A shortage of prison officers caused delays in ILWHA's health care facility visits as they were forced to go en masse even if their appointment fell on different dates:

"There are times that they [prison health care staff] jump our appointment. ... sometimes there could be even a shortage of guarding police. They just trick us saying, 'They went to court; guarded private permissions; got a duty'." (30 years old, male prisoner; Prison ' $B$ '). 
Among inter-institutional factors, poor organisational relationships between prisons, health care facilities as well as courts presented a substantial barrier to ART adherence. A lack of collaboration between health care facilities and the correctional system resulted in interruptions of ART during prison entry and transfer of ILWHA between correctional facilities. A prisoner who had been using ART before incarceration discussed his experience of the challenges of pursuing ART during prison entry:

"-_-_-Then the hospital on its turn said, 'We don't treat him unless we receive a referral!' I just remained without medication in the middle and had no one to borrow some. The doctor from this hospital had contacted the one there [the hospital where he had been taking the medication before imprisonment] and handed me a referral to receive treatment at 'Hosanna' Hospital." (35 years old, male prisoner; Prison 'A').

ART service providers described the difficulties in tracing back records of newly arriving ILWHA who had been using ART elsewhere, compared to non-incarcerated PLWHA who had been transferred in from other public health care facilities. As prisoners were often transferred abruptly, ILWHA often had limited opportunity to arrange consultations with ART service providers and complete their pre-transfer medication requirements:

"--_-Because he [newly arriving ILWHA] often comes suddenly. For example, they [prison staff] are not going to ask him when he will be leaving so that he can collect his medical information from the Hospital. They just pick him up and transport to somewhere. When other [non-incarcerated] clients want to change their residence, they just report to us --so, they will be given with the letter and go with their referral." (32 years old, female ART service provider; Health facility 'A').

Health care facility and court appointment times sometimes overlapped, leaving ILWHA oscillating between the two, with no power to influence a change for either appointment:

"---Then I got troubled when the hospital appointment overlaps with the court appointment. When I ask the court, 'I have a clinic appointment, could you please change the appointment for me?' He says, 'Are you the judge? It doesn't concern you! Shut up!' I just say 'OK!' Then when I come here [to the prison clinic] and inform them [prison health care staff], they say, 'Why didn't you go there [to the hospital] yesterday? Wasn't your appointment yesterday? I say, 'I went to the court!'” (35 years old, male prisoner; Prison 'A').

This situation led ILWHA to perform medically discouraged acts such as using unprescribed medications borrowing from fellow inmates. The aforementioned inmate went on to describe the negative impact of the circumstance on his medication use:

"--we also used to borrow [meds] from each other here with 'Usman' and 'Feleke Girma'. Sometimes the health facility appointment overlaps with court appointment." (35 years old, male prisoner; Prison 'A').

*Individuals' names used in this quote are pseudonyms.

Moreover, restrictions on movement associated with imprisonment itself presented a barrier to accessing required medical support. ART service providers noticed considerable difficulty in reporting drug side- 
effects in incarcerated clients compared to non-incarcerated clients:

"Some clients complain about [drug] side-effect such as headache, nausea, dizziness and itching. So, when people in the community experienced this or any other problem while taking the meds, they come quickly within two days, three days or four days. But they [prisoners] don't have this opportunity." (41 years old, male ART service provider; Health facility ' $B$ ').

The health administrators tended to accept that ILWHA accessed ART services from external health care facilities as normal practice, on the basis of perceived difficulty of introducing ART services within the prison system:

"--_-So, going to the hospital is the only option they [ILWHA] have and it doesn't matter if they go there every month; no other option!" (47 years old, male health agent; Zonal Health Department 'A').

Although some ILWHA tended to prefer external ART visits, despite its being physically demanding, others perceived it unrewarding. In the first case, ILWHA saw external visits as an opportunity to get some refreshments while being out of the very restricted prison environment:

"Let it be, that is not what matters most [travelling to the external health facility on foot]. We stay here locked, it can be a means to get fresh air and stretching feet. When you get out of here, you enjoy the air outside. I don't think I have difficulties with that." (35 years old, male prisoner; Prison 'A').

Other ILWHA, however, were reported by prison health staff to be reluctant to undertake external ART visits, giving greater priority to their work within the prison than their medication:

"There are some [ILWHA] who are very busy doing different business activities within the [prison] compound. They beg me, 'Please Sister, let someone bring me the meds! My business gets interrupted." (35 years old, female prison health staff; Prison ' $B$ ').

An ART service provider, who was caring for the same ILWHA as the above mentioned prison nurse, explained the difficulties in providing adherence support for such ILWHA:

"There are prisoners who do private work in the prison. It is hard for them to receive feedback on CD4 count and adherence because they send others to bring the meds for them." (41 years old, male ART service provider; Health facility ' $B$ ').

\section{Insufficient health staff support}

Prison health care staff appeared to feel little responsibility towards ILWHA given HIV treatment services operated entirely external to the prison healthcare system. Both prisoner and service provider participants discussed the deficiency of HIV care provided to ILWHA via the prison healthcare system. As one prisoner stated, prison health care staff were not considered central to HIV care in the prison system: 
"There is nothing we obtain from them [prison health care staff]; we should take our medication properly. They just send us to the hospital based on our appointment. We may get treatment from the clinic for other diseases just like any other prisoners. Our contact is with the hospital staff not with them." (38 years old, male prisoner; Prison ' $B$ ').

Perhaps due to the reduced sense of connection they had with prison health care staff, ILWHA reported lacking confidence in the prison healthcare system to offer them appropriate care. This made them totally reliant on external ART services, which were only provided on an appointment basis:

"Because I can explain my personal problems there [at an external health facility]. If it [HIV medication] comes here, it will require a long process to go there. I use the opportunity to get other benefits in terms of medication use. I eagerly await for the date to explain it to my doctor when I feel any discomfort. If you tell this to the staff here, to be honest, they may not respond well." (38 years old, male prisoner; Prison 'B').

Prison officials discussed the challenges that they faced in making referrals because of ILWHA's lack of confidence in the prison healthcare system. They suggested an imbalance between the community and prison healthcare systems in terms of resource allocations:

"--_-Secondly what I would add is that we are now having trouble making a referral. So a work position which encompasses doctors should be designed. There is one at a hospital, there is one at a health centre, why is it limited for correctional facilities? It would be nice if a position which includes doctors was designed jut to avoid unnecessary complaints like, 'There is no a doctor; this is a nurse!"' (32 years old, male prison administrator; Prison ' $B$ ').

Lack of regular health care staff support was identified as a driver of self-harming in ILWHA and even suicide attempts. The lack of support was underscored by the stated comfort derived from their discussion with the researcher:

"I have tried this thing [a suicide attempt] over and over again. But thanks to God I have forgotten it at least for now as I see you. I'm so excited now to be honest! It would be a great freedom for me if there was a person who regularly talks with us just like this; it doesn't matter whether he gives me nothing; I would be so happy! We are just thrown in here just like an object." (35 years old, male prisoner; Prison 'A').

Possibly due to limited HIV related training, prison health care staff appeared to encourage or perform repeat testing for ILWHA who were on ART. This increased the risk of discontinuing medication as a result of false negative results attributed to inhibition of viral replication by their medication:

"They [ART service providers] could have even reinitiated him [HIV infected prisoner who had been using $A R T$ before incarceration] on treatment after having tested as a new client and measured his CD4 count at the hospital." (29 years old, female prison health staff; Prison ' $C$ ').

The desire for repeat testing also arose amongst ILWHA, who assumed that their HIV infection had resolved as a result of their medication. A prison nurse described this situation and the 
misunderstandings among ILWHA:

'"My weight rises steadily and I don't feel any discomfort even if I do a lot of heavy works all day!'[as a prisoner on ART said to her]. 'Is HIV a painless disease?' Last time, they came mixed with others and had the test. Many of them say, 'Am I cured?'" (35 years old, female prison health staff; Prison 'B').

Prison officials stated their belief that their health care staff had an acceptable range of educational background, but there was an urgent need for updating professional training in order for them to align with rapid changes in HIV management. They described the scarcity of professional training again as being associated with a generally low interest of health agencies in the prison healthcare system:

"----It is due to inattention by organisations that offer training. If you take the Zonal Health Department, it just ignored our institution assuming it as a regional institution while giving the opportunity to the districts and even to the provinces including the [community] health extension workers. They don't give training for our staff. We complained about this in a forum held last year and the year before, 'These professionals need to have capacity building training, they need to update themselves to undertake their professional work appropriately, although they have their own professional scale!' but they don't hear us." (32 years old, male prison administrator; Prison 'B').

In acknowledging complaints made by the prison officials about inadequate health care staff training, health administrators tended to blame higher health agencies, such as the Regional Health Bureau, for their inequitable delivery of professional training between the community and prison healthcare systems. Ultimately, prison health care staff were not receiving HIV related training because ART services were delivered entirely external to the prison healthcare system:

"They [prison administrators] often complain about their health staff being neglected [in terms of professional training]. ... even the Regional Health Bureau gives more focus to public health care facilities. We have recently implored them a lot to train the health professionals there [at prison]. Nonetheless, their training level is insufficient because prisons are not ART sites." (53 years old, male health agent; Zonal Health Department 'B').

When asked, health administrators appeared unable to consider what circumstances might lead to the introduction of ART service in the prison settings:

"Right now it is impossible to open ART site at the prison. I don't know if the government or other agencies assign someone there particularly at correctional facilities where a large number of HIV infected inmates are found." (47 years old, male health agent; Zonal Health Department A).

Because of limited communications from ART service providers at public health care facilities, prison health care staff lacked knowledge about how effectively ILWHA were using their medication:

"They [ART service providers] never give us feedback. I don't actually know whether the prisoners' CD4 count is declining or viral load rising...; I think it's every six-month that viral load is measured, I'm not sure 
whether they perform it or not." (29 years old, female prison health staff; Prison 'C').

ART service providers also described an almost complete lack of communication between themselves and prison health care staff; one even indicating that their knowledge of prison health staff was solely derived from their participation in the current study:

"Never. It was your study that made me know that girl [a prison nurse], her phone and even about the correctional institution itself; I have never thought of it. We never had a communication with the health care staff there rather with the prison officers who bring inmates here, just to get the inmates." (32 years old, female ART service provider; Health facility ' $A$ ').

The ART service providers' limited understanding of the context of HIV care for ILWHA may have contributed to the low HIV care uptake among ILWHA at some external health care facilities. ILWHA commonly discussed the need for self-motivation in managing their treatment as they were only rarely receiving adherence support from ART service providers:

"-_-I was provided with the counselling service the first day. I have been striving by myself since then. --once the doctor has prescribed it for me, 'You have this disease!' It's a doctor next to God. He gave me this saying, 'Just use this if you want to live tomorrow!' I'm using it just to see tomorrow. But [Clapping his hands] I haven't received any advice since then." (38 years old, male prisoner; Prison ' $C$ ').

Some ILWHA were found to be unaware of the possible adverse consequences of interrupting medication use:

"How do I know that? I don't know about the consequences of missing the medication because I have never missed my medication. As I said, there might be a lapse of few minutes." (38 years old, male prisoner; Prison ' $C$ ').

ART service providers appeared to vindicate their incapability of providing optimal care because of the high volume of patients they were managing. They were therefore unable to guarantee whether ILWHA were properly using the medication that they had been collecting:

"Because we have a lot of patients to deal with-_---there are gaps in our side too. When you ask him like, 'Are you taking the medication?' If he says 'Yes!' Then you will let him go just providing him with the prescription and taking his weight. But we don't know whether he takes it or not." (32 years old, female ART service provider; Health facility 'A').

\section{Uncooperative security systems}

Interruptions to medication use occurred at different stages of the incarceration process due to uncooperative security systems. One prisoner who had started ART before imprisonment discussed being prevented from accessing his medication during arrest and the delays that subsequently occurred in his medication continuation because of the absence of ART services in the prison system: 
"I told this to [an ART service provider], the police denied having my medication with me during arrest. I was arrested suddenly by the police on my way to home. 'Don't move back!' they said. I implored them, 'I'm a patient, let me just have my meds with me!' 'You'll take medicine from Hosanna Hospital!' they replied. 'I did not take the meds for three days." (32 years old, male prisoner; Prison 'A').

ILWHA's treatment adherence after prison entry was also considerably constrained by protracted security processes. Incoming ILWHA were obliged to remain without medication until the police investigations were completed about any medications they may have had with them on arrest:

"I was troubled the first day [during entry]. It was because the security had taken away my drugs for a check by the health staff, and this took a while. I eventually got it after a lot of hustle." (32 years old, male prisoner; Prison ' $C$ ').

In addition to the sense of a diminished responsibility towards ILWHA exhibited by prison staff, prison security presented an additional barrier to accessing supplementary medications available in the prison system:

"He is a treatment facilitator. He is the one who lets us see her [a prison nurse]. It is really hard even to come here! Oh, I can't come here if I have some stomach-ache, and she knows this. I gently explain to him this because he should not be offended. Then he says, 'Wait!' He takes me here [to the prison clinic] if he is happy to do so. Sometimes I prefer to get hurt on the day they are annoyed by other people." (35 years old, male prisoner; Prison ' $A$ ').

Prison security related factors also impacted the quality of care delivered by ART service providers. Prison officers' often allowed insufficient time for ILWHA-ART service provider discussion and laboratory investigations, which influenced ILWHA's care use:

"-_-_-Even after they have arrived at here [an ART site], they cannot receive appropriate adherence support and laboratory results like other clients do. The guarding police are unwilling to go out for us to talk privately with the clients. ... They tend to insult us if we are to take some time to discuss with them."(32 years old, female ART service provider; Health facility ' $A$ ').

The same participant discussed the emotional trauma of ILWHA caused by the presence of prison officers during their consultation, and how this affected the ILWHA's intention to speak freely with their clinician:

"Oh! They [ILWHA] don't even say a word! When you ask them about something, they just become restless and lack confidence because those persons [the prison officers] are unwilling to stay out. They just feel restless and almost we don't talk anything except something like saying, 'How are you? Are you taking your meds? Is there any problem?' 'No problem!' they reply; they don't talk anything more." (32 years old, female ART service provider; Health facility ' $A$ '). 
One of her ILWHA clients witnessed a prison officer's intrusion in a client-health care provider discussion and the argument that resulting in ILWHA being taken away from the health care facility before their consultations were completed:

"They [prison officers] don't allow us to stay there. She [an ART service provider] insulted them sometime and told them, 'Don't do this, you may also be arrested tomorrow!' She said this because she saw what they were doing to us. If in case treatment delays, they just rush us off saying, 'Let's go! We've brought you to the hospital, we have been told just to do that!'” (35 years old, male prisoner; Prison 'A').

\section{Loss of patient privacy}

Both prisoner and service provider participants discussed challenges in relation to keeping patient privacy and confidentiality within the context of the prison system. Congregated living conditions and regular external ART visits (often guarded en masse) contributed greatly to loss of privacy. A prisoner who had been taking ART in prison for six years explained circumstances when patient privacy was affected for ILWHA in relation to their HIV status:

"--you know what happens in this [prison] compound, he [HIV infected prisoner] may attempt to hide for some time, but people will make it overt soon. Since we live in the same compound, every prisoner is aware of who has the virus and who doesn't." (38 years old, male prisoner; Prison 'C').

One prisoner who had not previously disclosed his HIV status described his experience of having his medication divulged during external ART visits, and his struggle to keep his diagnosis confidential. Prison staff and fellow inmates became suspicious of his being HIV infected because of his regular external ART visits and security checks at the gate:

"I prefer the medication itself would be dispensed here with my nurse offering it inconspicuously. You know what, when you go to the health centre regularly, people become suspicious [of being HIV infected]. And in your check-in, prison security fumble into your pocket and may bring the meds out." (32 years old, male prisoner; Prison ' $D$ ').

He was therefore obliged to take his medication at a time when all his roommates were out, which in his perception was inconvenient as it prohibited him from resting appropriately as medically recommended:

"---when I say untimely [referring to medication use], the instruction says you have to have some rest after having the drugs, but in my case, since people don't go to bed until 11pm or 12am, I take it at 4pm; there will be no one in the living room at that time [as they go to the Mosque]." (32 years old, male prisoner; Prison ' $D$ ').

ILWHA who had strong social networks in the immediate communities of the prison settings were reported to be less comfortable in their interactions with health staff than those who were from remote areas. One ART service provider described what he noticed of the situation:

Page $13 / 29$ 
"They [HIV infected prisoners] came from different areas so there are some who know the local community and there are others who don't know. They come en masse. We notice that those who know the local community often get embarrassed. Those who came from somewhere else don't care." (41 years old, male ART service provider; Health facility ' $B$ ').

Patient privacy was also impacted by casual communications between prison health care staff and ILWHA. Prison health care staff were unable to maintain patient privacy, which was challenged by the highly exposed prison environment. An undisclosed HIV-infected prisoner shared his lived experience of loss of privacy during contact with a prison nurse:

"Rather patient privacy is severely divulged here in the prison. One day he [a prison nurse] called me and asked 'Where are those who got diagnosed with you?' There were a lot of prisoners around me when he was saying this. I was so embarrassed. It should be me and him who should know about this, isn't it?" (32 years old, male prisoner; Prison ' $D$ ').

As correction staff responsible for accompanying ILWHA to ART visits were frequently changed, inmates' HIV status was constantly disclosed to different people at different times without consent. One ART service provider argued for specified prison officers to escort ILWHA to alleviate the problem of privacy loss at least to some extent, recalling similar situations from his previous experience to support the claim:

"It is not just one person who knows them. What I heard in ART training was that clients complain about frequent changing of cleaners; ... Why not only one person?... You see the case of the guarding police? They are different prison officers who bring them at different times." (41 years old, male ART service provider; Health facility ' $B$ ').

\section{Social stigma and HIV status disclosure}

Some ILWHA who had been using ART before incarceration felt unable to disclose their HIV status and/or their previous use of ART to prison staff and were therefore more likely to discontinue their medication. A prison officer who often took ILWHA to external ART sites came across such a situation:

"... There are people who are aware of their HIV status prior to prison entry and got into without disclosing their status. However, it will eventually be revealed when his health condition gets worse." (39 years old, male prison officer; Prison ' $C$ ').

ILWHA were discouraged from disclosing their HIV status because they had observed that it resulted in adverse consequences such as enacted stigma to those who had performed the course of action. One prisoner said that he preferred to keep his HIV status secret to avoid potential maltreatment by his fellow inmates:

"Yes, I haven't disclosed to anyone. I was imprisoned in this prison before, and there was a guy from another town, because he has HIV in his blood, no one wished to have a meal with him, they let him eat alone. They prohibited him from using water and tea utensils together. This is why I preferred to hide my

Page $14 / 29$ 
status. Doesn't matter if it was outside, nobody does anything to you, and you would live your own life yeah, but here......" (32 years old, male prisoner; Prison 'D').

Perceived stigma dissuaded ILWHA from disclosure due to its possible adverse consequences such as emotional suffering, which might prevent them from participating in prison social life:

"Nothing but a psychological trauma [if disclosed]. You know, these are uncontrolled people. When they call you, 'You ill!' you may feel embarrassed, tortured and get annoyed all day." (32 years old, male prisoner; Prison ' $D$ ').

The effect of stigma on ILWHA appeared to be even more intense when it was enacted by prison officers, often leading to despondency:

"You know they [prison officers] consider me as dead $\square$ they perceive me as if I carry death like a laptop. I'd love to see if they are provided with a sort of training and I wouldn't be tortured mentally." (35 years old, male prisoner; Prison 'A').

Nonetheless, prison health care staff and health agents reported that incoming ILWHA should have announced their HIV status to prison staff to ensure continuation of their medication. They appeared to possess diffused responsibility for offering ILWHA appropriate professional support. A prison nurse explained that she wasn't in a position to help incoming ILWHA if they were unable to inform her about their HIV status:

"-- However, if there is someone who is arrested and doesn't speak to us, we can't help. We haven't yet examined them while entering." (35 years old, female prison health staff; Prison ' $B$ ').

Incoming ILWHA who felt able to disclose their HIV status and/or their previous use of ART to prison staff were less likely to experience medication interruptions that often occurred during prison entry. One female inmate who had been on ART before imprisonment reported her lived experience regarding this:

"After I told the security at the police station that I had a prescription, my family brought me my medication card, and then I went to the hospital with the police to continue my medication. And I told the prison officers myself and then they informed the prison health staff." (45 years old, female prisoner; Prison 'A').

Some inmates believed that their capability to disclose their HIV status dispelled possible embarrassment (perceived stigma) and enabled them to confidently use their medication, as well as to interact with members of the prison communities. It helped them obtain peer support essential to manage their medication use within the context of custodial settings:

"The time a guy died of HIV; while I was playing with one of my friends, two guys came to us, and I heard one of them saying to my friend like, 'Take care not to be pricked by that guy's nails!' Even I myself got embarrassed at that moment [Laughs]! And I just went away laughingly; I never get embarrassed because 
everyone knows about it. I just talk to everyone; I don't hide it! Why would I? I even ask them to tell me the time to take my medication as my watch is not working now." (45 years old, male prisoner; Prison 'D').

Disclosure was also perceived by some ILWHA as a means to promote positive living standards that are important for supporting themselves and others in similar situations (i.e. PLWHA) to shape their life prospects through sharing their lived experiences with each other:

"--Thus, it means nothing to me if I disclose my status. Because the point here is to enable everyone who is in a similar situation to lead his life as myself. You will only be able to have a clear conscience when you disclose yourself to others rather than hiding or covering it. It has a big impact in your life; you will obtain what you need to obtain, and live normal life just like this." (32 years old, male prisoner; Prison 'C').

ILWHA who were able to accept their HIV status were capable of coping with privacy affecting prison environments and demonstrated a high level of confidence to pursue normal life while using the medication. Their self-confidence enabled them to also cope with negative responses from others in regard to their HIV status:

"I can't do anything even if it [stigmatisation by fellow inmates] exists, I just ignore it. They can say whatever they want to say, I don't care about that." (35 years old, female prisoner; Prison 'B').

\section{Food supply insufficiency}

Almost all prisoner participants reported insufficiency and poor quality of food in the prison system. Most of them perceived that the poor quality of food caused more suffering to those who were using ART. Anticipating its possible negative effects on the health benefits of the medication, an inmate favoured taking the medication before a meal, which was against instructions:

"---The drugs and the food we eat are totally irrelevant, particularly the bread... it looks like something made of mud! And the sauce... I'm not sure whether they cook it well. It is really unappetising with the medication. I take my medication on empty stomach fearing that it may provoke nausea. Although unpleasant, it is better to eat it after taking the drugs unless it may affect the effectiveness of the drugs." (32 years old, male prisoner; Prison ' $C$ ').

This inmate perceived that the adverse side-effects of the medication were completely dependent on an appropriateness of the food that he was consuming, and would cause no harm if proper food was taken:

"It is a good medication once you have an appropriate diet; it is a nice medication. I had never had any bad feeling due to this medication [when I was outside prison]. What matters most is what you eat and the way you eat." (32 years old, male prisoner; Prison 'C').

ILWHA reported being challenged to maintain their medication use, often ascribing their vulnerability to drug side-effects to their impaired physical states produced by insufficiency of food. They felt uncertain 
about being capable of pursuing the use of medication in the face of combined adverse effects of poor quality food and the medication itself:

"Sometimes I skip the meds when I feel empty stomach after having eaten this dry loaf of bread ... It makes me like fatigued. ... I can't even laugh loud, my heart feels dry, and my throat feels dry -_-_" (35 years old, male prisoner; Prison 'A').

Insufficiency of food sometimes led ILWHA to relying on religious beliefs to retain health in place of their medication:

"I'm suffering a lot because of the food. To tell you the truth, I came here because I was a convicted criminal; I wait with prayers and with God until I will be released once I served my sentence." (38 years old, male prisoner; Prison ' $C$ ').

At some prison settings, inmates reported insufficient access to other basic necessities, including to drinking water:

".... I often get troubled to get some water to take my meds; I get so hurt when they [prison security] say, 'Just queue with others to have water!' It is with hustle and bustle you could get some water and only the gangs take it." (35 years old, male prisoner; Prison 'A').

ART service providers experienced a challenge while verbally persuading their prisoner clients to adhere to the medication instructions, as ILWHA held poor self-efficacy to pursue the course of action because of the food:

"There are individuals [ILWHA] who complain about the food provided by the prison and say, 'We're almost burned, the meds are burning us! We're taking this medicine with that food!' They have too much complaint about the food." (41 years old, male ART service provider; Health facility ' $B$ ').

However, prison officials failed to respond to this, although they often did recognise ILWHA had greater dietary requirements than ordinary inmates because of their medication use. They often blamed funding agencies for their limited budget allocation for necessary additional food rations for ILWHA:

"You know what? Considering that [rations] we see them [ILWHA] as prisoners. It is 0.7USD [United States Dollar] a day, 20USD a month. There is no exception to him, he is fed in the same manner as other inmates are. Of course, it's not enough. First, HIV patients should get balanced diet...It is problematic that there is no any additional support other than the normal budget allotted for other inmates." (45 years old, male prison administrator; Prison ' $C$ ').

At the community level, while there had been a substantial number of supporting agencies outside prison working on nutritional issues with PLWHA, the prison system seemed to be in isolation from such programs as it lacked due attention from these agencies: 
"Yes, non-governmental organisations [NGOs] such as What-sup, Nastad and others too, they are about three but I don't exactly remember their names, and they carry out supporting works in the community. They give them [PLWHA] money and grain. Catholics also help them. Our main duty is just giving treatment, but if the [prison] clinic had some social linkage, they would have supported them as well." (41 years old, male ART service provider; Health facility ' $B$ ').

\section{Facilitators of ART adherence}

\section{Social support}

Prisoners described the importance of social networks for enhancing ART adherence in prison. In their view, social networks serve as a means for ILWHA to offer each other information, material and emotional as well as affectionate support. Through social networks, senior ILWHA would encourage incoming ILWHA to disclose their HIV status in order to access health care and support. An inmate who had been using ART in prison for four years reported the benefits that ILWHA used to gain from such a network:

"We used to get together every month; we used to help each other when there was anyone who is seriously sick; we used to give him money from our common account. If it was in the past, they [incoming ILWHA] would report to the club, and then we would let the concerned body know that there are new arrivals. We would receive them kindly." (45 years old, male prisoner; Prison ' $C$ ').

The later loss of such social networks meant that ILWHA also lost the medical attention they used to have as patients on a continuous therapy:

"Previously, we had our own leader thus, we were given the priority when we got sick; we didn't register to wait for turns. We came here [to the prison clinic] first. We came here instantly and received the care. There are no such things now! No one is even concerned about you. It is horrific! If our turn is not up today, we should wait overnight, and this is hard for us as we continuously take medications and we may not get treatment on time." (45 years old, male prisoner; Prison ' $C$ ').

The social networks also used to function as a means to earn income for accessing supplementary food and transport to external ART sites. It fostered cooperation amongst ILWHA to run various business activities otherwise might be difficult to carry out individually in a prison environment:

"We had our own barbershops, table tennis and other stuff; we made monthly meetings. These were things that we rely on to have some coffee and tea. They would have allowed us to run our club so that we could have covered our transport costs." (45 years old, male prisoner; Prison 'C').

ILWHA also believed that social networks have the capacity to dispel dejections, and avoid alienations by HIV non-infected prisoners:

"At the time we had the club, we used to get together and talk to each other about our daily problems. When we did that, we got a sense of relief. But now, everyone particularly the healthy ones point their 
finger at you, 'He's like-_--medication!'” (45 years old, male prisoner; Prison 'C').

ILWHA considered socialising with their peers as a means to share their lived experiences of how to effectively adhere to the medication, and gain some sort of comfort while living in such congregated settings being ART users:

"It would be difficult for me if I lived alone being a [ART] user with a thousand of inmates. But now as they [other ILWHA] are with me, I learn many things from them. There is a guy who has been using for eleven years and we discuss a lot with him. He teaches me about the medicine and other stuff; I learned a lot from them, they help me. I'm glad to have them." (25 years old, male prisoner; Prison 'B').

One prisoner discussed how he felt after losing his friends due to a transfer out to other prisons, recalling the value of their affections and companionships in making things easier for him in a prison context:

"I felt some sort of imprisonment afresh after they [his ILWHA friends] had been transferred to another prison! We use to chat being there [at a hut], we laugh and play together, and talk with each other. It was really nice when we were three or four. Now I'm alone." (35 years old, male prisoner; Prison 'A').

Close living circumstances amongst ILWHA was also found to determine an appropriate use of ART as it appeared to be essential for them to support each other to stick to their medication schedule:

"A person next to me also uses the medication. We live in the same room. My bed is just here and his bed is over there [Showing the position]. We sometimes help each other not to forget our medication time." (38 years old, male prisoner; Prison ' $B$ ').

Notwithstanding the value of the social networks for ILWHA, some prisoner participants reported a denial of the resources that used to be offered in their prison, which were essential for the existence of the associations. Participants related this to unresponsive prison officials who undermined the seriousness of HIV infection:

"We asked them [prison administrators] to allow us to run the club by ourselves; to help anyone in a serious health condition. They denied it although we have the capacity to work. We have appealed a couple of times to the office. Someone in the office once ironically responded, 'You call this [HIV] a disease? This is a kind of an ordinary illness!' He added, 'Why you speak like this?'" (45 years old, male prisoner; Prison ' $C$ ').

The prisoners suggested a reduction in number of ILWHA as a reason for the prison officials' rejection of their claim. However, they argued that the social network could attract a substantial number of ILWHA who might otherwise choose to remain undisclosed:

"...they [prison administrators] say, 'You are only few!' You are only few! People come together when they find their likes. There could be many people who would join us." (45 years old, male prisoner; Prison 'C'). 
Health agents also reported that prison officials paid little attention to issues related to HIV. The prison officials tended to give more focus to other duties while undermining the importance of HIV in their institutions:

"The other thing is it [HIV issues] needs emphasis by the [prison] administration. The focus of the administrators is only minimal; due to being busy with other jobs, with the politics, with other internal stuff. Sometimes they don't even think that there is HIV [Laughs]!" (47 years old, male health agent; Zonal Health Department ' $A$ ').

Furthermore, prisoners tended to blame health agencies for the decline in care and support at the prison system including social networks. As they perceived, health agencies' ignorance of HIV issues at prion settings inflicted suffering on ILWHA:

"The anti-HIV club should have been closely monitored with governmental and non-governmental organisations taking part. I don't think the club is recognised by the government; it rather seems that people voluntarily support us. I don't think the government recognises that there are people living with HIV in prison; whether we are alive or dead." (38 years old, male prisoner; Prison 'C').

There was an inequitable distribution of resources important for the establishment of such social networks between incarcerated and non-incarcerated PLWHA; the former being devoid of health agencies' due attention. One ART service provider described the alienation of PLWHA at prison settings from various social activities that were undertaken in the community, which served as an important point for dissemination of information for affected people:

"They [prisoners] are very isolated in this perspective. Because there are training sessions that I often go and offer them [PLWHA in the outside community]. HIV positive people will be called and get organised, and provided with [life skills] training. There are associations called 'Tesfa' meaning 'Hope', "litinne' to mean 'With Love'... OSA [Orphan Support Africa], --. So, they have a very slight chance of getting training compared to people in the outside community. No one even remembers at first place to invite people from prion [Laughs]! I mean there is no one who thinks there are patients at prion [Laughs]!" (32 years old, female ART service provider; Health facility ' $A$ ').

Health agents acknowledged that the benefits of social networks had been clearly demonstrated in the community settings for PLWHA. They were operating as a means to gain government agencies' attention and build self-confidence among PLWHA to share each other their lived experiences, and run various income generating activities. However, the health agents recognised the scarcity of such social networks at the prison system, ascribing this to the instability of prison populations and restrictions inherent to prison settings:

"There are associations related to HIV in the Town. There is an association called "litinne", meaning "With Love" which works closely with us. They have an association so that they have nothing to fear; they stand in front and teach; they trade like a normal person. There are also members from the prison staff 
who disclosed their status and use the opportunity. The situation of prisons is quite different; they are a little strict [Laughs]. It's not a house you knock to get in; it has its own time to get in and out; it is quite tight." (47 years old, male health agent; Zonal Health Department 'A').

\section{Prison as a facilitator of ART adherence}

Imprisonment encouraged some PLWHA to refrain from behaviour which adversely affected their ability to appropriately use ART. One prisoner reported:

"I started taking the meds properly after I became imprisoned. When I was out there, I used to smoke forty cigarettes per day, I also used to chew "khat". I was so desperate! Since I came here, I just started to think about and wondering what was going on, where I'm going to; then I entered Church, quit my addictions, refrained myself from being with addicted friends, my reduced CD4 [count] shown some gains as I have got checked for it last time." (35 years old, male prisoner; Prison 'A').

ART service providers observed some behavioural changes amongst their clients during incarceration with significant improvements in treatment outcomes. They tended to relate this to less accessibility of undesirable social networks that existed outside prison:

"Sometimes I see incarceration as an opportunity. There were clients who had behavioural problems, and addicted to substances like cigarette and had an adherence problem. However, after they had got into there [prison], they don't think of other things, they only think of their medicine: they don't smoke, they don't use "khat", so it's just their medicine; there are people whose adherence has improved. Yes, their viral load and CD4 count are better; even better than those in the outside community." (32 years old, female ART provider; Health facility ' $A$ ').

Imprisonment was found to offer conducive social environments for ILWHA to learn about the adverse consequences of medication interruption from peers who had experienced these consequences:

"There were persons whose feet got paralysed and had some inflammation on their body ldue to medication interruption]. Then they went to the hospital, continued their medication and then the signs disappeared. Then I say, 'What's the matter if I take this little thing [the medication]! Isn't this easier than what I have every time?'” (30 years old, male prisoner; Prison 'B').

\section{Discussion}

This study investigated various barriers to, and facilitators of, ART adherence amongst ILWHA in South Ethiopia. As well as social and individual level factors, prison system structural factors appeared to play a crucial role in determining ILWHA's ability to appropriately use ART. Overall, there was a lack of socially agreed principles that justify appropriate distribution of healthcare resources between the prison and community healthcare systems, leading to sub-standard HIV care in the prison system. Prisoner participants perceived the situation as 'a double burden' of being imprisoned and having inconsistent HIV care. The interplay between these 'burdens' exacerbated the adversities faced by ILWHA. 
Implementation of standard HIV care programs in prison is recommended by international guidelines [3739] and has proven to be feasible and effective both in high- and low-income countries [40-42]. This study strengthens previous evidence that most countries in sub-Saharan Africa (SSA) lack comprehensive policies supporting this recommendation $[43,44]$, which may lead to sub-optimal treatment outcomes and facilitation of community transmission [1-3].

Most institutional and inter-institutional barriers presented by external ART services in the current study are commensurate with findings of other investigations in low-income countries [25, 26]. A lack of transport facilities combined with shortage of escorting prison officers led to group clinic presentations, which in turn caused frequent missing of clinic appointments, and use of unprescribed medications. Regular visits to external ART sites in a group and a frequent shifting of guarding prison officers severely affected patient privacy which is already challenged by congregated living conditions in a prison environment $[17,23]$.

Participants reported medication interruptions at various stages of the incarceration process, which related to the uncooperative security system. Denial of medication possession during arrest coupled with protracted security processes during prison entry forced incoming ILWHA to interrupt their medication. After prison entry, prison officers' obstruction of ILWHA-ART service provider consultations influenced ILWHA's care utilisation and caused emotional trauma and demotivation of reporting medical concerns. These findings are consistent with what Shalihu et al [23] reported in a Namibian prison, where prison officers' discriminatory threatening of ILWHA caused "frustration, humiliation and discouragement" in relation to ART use (page 971). Other studies have also described frequent medication interruptions amongst ILWHA due to uncooperative prison security even where onsite ART services are available [1618]. This underscores the imperative of creating awareness amongst security staff regarding the necessity of ART for ILWHA during every step of the incarceration process, as well as the importance of health care provider counselling and support for maintaining adherence [45].

There was insufficient health staff support for ILWHA both from the prison healthcare system and external health care facilities. The inadequacy of prison health care staff support was mostly derived from a lack of HIV related training and possession of dissociated responsibility for ILWHA (given ART services were provided externally), as well as poor communication with ART service providers. This drove ILWHA to have reduced trust in prison health care staff and instead rely on the external health care services, despite these services being largely inaccessible. Research shows that adoption of the belief that health care providers are uncaring and unsympathetic negatively affects ART adherence [17]. The prison health care staff's limited HIV care skills were further noted by their encouragement to undertake a repeat testing for ILWHA who were already on ART. This usually produces false negative results due to viral suppression by the medication and increases the likelihood of medication discontinuation [1].

HIV care provided to prisoners by external ART clinics was also found to be suboptimal. This was demonstrated by a lack of continuous counselling and support during and after initiation of ART. Optimal health care provider support is crucial for maintaining ART adherence in ILWHA $[13,17,18]$, however, the 
inadequacy of trained health care staff remains a challenge in many prison systems [15-17]. Thus, provision of HIV related training for prison health care staff is highly recommended in addition to strengthening communication between prison and community healthcare systems [46].

According to the service providers, ILWHA were required to disclose their HIV status and/or previous use of ART to prison staff if they were to continue their medication. However, this study and others [47] found that ILWHA often lack the confidence to disclose their HIV status to prison staff, often disclosing only when their health worsened due to the progression of infection. Vicarious and direct experiences of social stigma by fellow inmates and prison officers plaid a role in hindering ILWHA's motivation to disclose their status, and so lessened their commitment to use ART. The impact of debasement was more intense when enacted by prison security often leading to despondency, the main predictor of ART non-adherence in incarcerated people $[9,10,18,22,24]$. This supports the well documented negative influence of marginalisation and discriminatory treatment on ILWHA's ART adherence on the basis of HIV status [15, $17,18,23]$.

Despite the absence of organisational structures supporting disclosure and ensuring patient privacy in the prison system, ILWHA who felt able to disclose their HIV status were able to reduce potential medication interruptions [16] and to create sources of social support. Disclosure also served a means to gain self-confidence important to cope with social stigma, and internal satisfaction and motivation to support oneself and others in a similar situation, as Sprague et al [48] puts it "generating a type of solidarity" (page 1437). This implies a need for interventions that enhance consented disclosure amongst ILWHA, while preserving patient privacy and confidentiality; increasing access to HIV counsellors and reducing social stigma through improving general understanding of HIV amongst prison staff and prisoners may facilitate disclosure [49].

In prisoners' accounts, imprisonment appeared to be more burdensome to ILWHA than their non-HIV infected counterparts in the face of food supply insufficiency. This is because the former group use a therapy (ART) that requires a higher quality diet. The insufficient quantity and quality of food aggravated ARV adverse-effects, which often predicts non-adherence (NA) in prisoners [10, 18-21]. It also encouraged some ILWHA to develop a tendency to rely on religious belief rather than ART for their health. The use of spiritual medicine instead of ART is one of the main behavioural causes of ART discontinuation in the general population in Ethiopia [50] and elsewhere in SSA [51, 52].

Food insufficiency was partly attributed to structural factors that reflected to the denial of prison officials of the need for additional food support for ILWHA, as well as unfair distribution of supplementary food by health agents that favoured PLWHA in the outside community. The influence of food insufficiency on ART adherence in this study is consistent with findings of studies in SSA $[23,26]$ and other low- and middleincome countries elsewhere [14,20], which reported frequent missing of doses and treatment interruptions amongst ILWHA due to hunger. Efforts should be made to enhance food support programs in prison settings and give special focus to ILWHA in the nutritional programs designed to support PLWHA at public health care facilities [53]. 
The social networks of ILWHA were found to operate as an essential source of social support including instrumental, emotional, affectionate and information support. With the help of the social networks, ILWHA were able to run various business activities together to afford different necessities such as additional diet and transport to ART sites, and help each other emotionally to dispel dejections. The social establishment also acted as a means to gain vicarious experiences related to medication adherence, avoid social stigma and encourage each other to disclose and evade structural barriers to access care. Nonetheless, most prisoner participants described a decline in such social networks due to denial of resources by prison administrations and little attention by health agencies. The importance of social support for maintaining ART adherence in prisoners is well recognised $[9,11,13,21]$, suggesting a need for enhancing peer support programs in prison settings.

One prison-related factor appeared to facilitate ART adherence through various mechanisms. It assisted ILWHA to re-assess and correct risky behavioural patterns that might have existed prior to their incarceration in relation to their medication use. Due to reduced access to their former social groups in which risky behaviour was entrenched, some ILWHA achieved better adherence to ART compared to other PLWHA. Imprisonment also created a conducive environment for ILWHA to learn from others about the negative health effects of risky behaviours such as discontinuation of ART. With a number of studies reporting improvements in ART adherence during incarceration in settings where there is a standard HIV care $[41,42,54-57]$, these findings provide additional evidence on circumstances that may facilitate the effectiveness of comprehensive ART programs in prison settings.

Our study included prisoners who had been on ART for a relatively long period of time, but challenges of adherence may vary depending on level of ART-related experience. Most barriers to, and facilitators of adherence identified in this study were consistently identified across the participating correctional facilities, suggesting the pervasiveness of the circumstances in Ethiopian prisons. However, larger quantitative studies are needed to draw conclusions that are representative of the prison populations. Further research is needed to more closely investigate the interconnections between patient privacy, disclosure and social stigma and their effect on ART adherence in a prison environment. Research is also required to investigate circumstances related to post-release care.

\section{Conclusions}

HIV care in the South Ethiopian prison system is likely to be improved if access to ART services is ensured. Access to standard care was substantially hindered by a lack of transport facilities, an insufficient number of security staff who were appropriately supportive, and poor communication between prison health care staff and ART service providers. Stigmatisation by fellow inmates and prison officers affected ILWHA's ability to disclose HIV status and led to despondency and a lack of commitment to use ART. Insufficient supply of food in the prison system combined with a limited access to community nutritional programs aggravated ARV side-effects, which in turn increased the likelihood of medication discontinuation. However, ART adherence was facilitated by ILWHA's: self-efficacy to disclose their HIV status and cope with the influences of social stigma, the presence of peer support, as well as vicarious 
experiences of adverse consequences of unhealthy behavioural patterns such as interrupting medication. Therefore, interventions that ensure: access to standard HIV care and health care provider support; preserve patient privacy and confidentiality, while promoting disclosure by reducing stigma; and enhance peer support and nutritional programs are strongly recommended.

\section{Declarations}

\section{Competing interests}

All authors declare no competing interests.

\section{Acknowledgements}

We would like to acknowledge the authorities of the participating Zonal Health Departments, health care facilities and prisons for offering permissions to conduct the study in their institutions. We would also like to appreciate all participants for sharing their lived experiences.

\section{Authors' contributions}

TGF conceived the research idea; conducted the interview; analysed and interpreted data; drafted the manuscript. GT and ERM participated in the coding of the interview data and subsequent revisions of the manuscript. All authors read and approved the final paper.

\section{References}

1. WHO. Consolidated guidelines on the use of antiretroviral drugs for treating and preventing HIV infection: recommendations for a public health approach. Geneva, Switzerland: World Health Organization (WHO); 2013.

2. WHO. Adherence to long-term therapies: evidence for action. Human immunodeficiency virus and acquired immunodeficiency syndrome. Geneva, Switzerland: World Health Organization; 2003.

3. WHO. Consolidated guidelines on HIV prevention, diagnosis, treatment and care for key populations: 2016 update. Switzerland: World Health Organization (WHO); 2016.

4. Ruperez M, Pou C, Maculuve S, Cedeno S, Luis L, Rodriguez J, et al. Determinants of virological failure and antiretroviral drug resistance in Mozambique. The Journal of antimicrobial chemotherapy. 2015;70(9):2639-47.

5. Chammartin F, Zrcher K, Keiser O, Weigel R, Chu K, Kiragga AN, et al. Outcomes of Patients Lost to Follow-up in African Antiretroviral Therapy Programs: Individual Patient Data Meta-analysis. Clinical Infectious Diseases. 2018;67(11):1643-52.

6. Haas AD, Zaniewski E, Anderegg N, Ford N, Fox MP, Vinikoor M, et al. Retention and mortality on antiretroviral therapy in subSaharan Africa: collaborative analyses of HIV treatment programmes. Journal of the International AIDS Society. 2018;21(2). 
7. UNAIDS. Joint United Nations Programme on HIV/AIDS (UNAIDS) data for 2019. Geneva, Switzerland: UNAIDS; 2019.

8. Dolan K, Wirtz AL, Moazen B, Ndeffo-Mbah M, Galvani A, Kinner SA, et al. Global burden of HIV, viral hepatitis, and tuberculosis in prisoners and detainees. The Lancet. 2016;388(10049):1089-102.

9. Uthman OA, Oladimeji O, Nduka C. Adherence to antiretroviral therapy among HIV-infected prisoners: a systematic review and meta-analysis. Aids Care-Psychological and Socio-Medical Aspects of Aids/Hiv. 2017;29(4):489-97.

10. Soto Blanco JM, Ruiz Pérez I, De Labry Lima AO, Castro Recio JM, Girela López E, Antón Basanta JJ. Adherence to antiretroviral treatment in prisons. AIDS research and human retroviruses. 2005;21(8):683-8.

11. Ines SM, Moralejo L, Marcos M, Fuertes A, Luna G. Adherence to highly active antiretroviral therapy in HIV-infected inmates. Current HIV research. 2008;6(2):164-70.

12. Subramanian Y, Khan MN, Berger S, Foisy M, Singh A, Woods D, et al. HIV outcomes at a Canadian remand centre. International Journal of Prisoner Health. 2016;12(3):145-56.

13. Mostashari F, Riley E, Selwyn PA, Altice FL. Acceptance and adherence with antiretroviral therapy among HIV-infected women in a correctional facility. Journal of Acquired Immune Deficiency Syndromes and Human Retrovirology. 1998;18(4):341-8.

14. Paparizos V, Kourkounti S, Leuow K, Georgoulas S, Kyriakis K, Antoniou C. Adherence to antiretroviral therapy among HIV-infected prisoners. Le infezioni in medicina: rivista periodica di eziologia, epidemiologia, diagnostica, clinica e terapia delle patologie infettive. 2013;21(3):189-93.

15. Small W, Wood E, Betteridge G, Montaner J, Kerr T. The impact of incarceration upon adherence to HIV treatment among HIV-positive injection drug users: a qualitative study. AIDS care. 2009;21(6):708-14.

16. Culbert G. Violence and the perceived risks of taking antiretroviral therapy in US jails and prisons. International journal of prisoner health. 2014;10(2):94-110.

17. Roberson DW, White BL, Fogel Cl. Factors influencing adherence to antiretroviral therapy for HIVinfected female inmates. The Journal of the Association of Nurses in AIDS Care: JANAC. 2009;20(1):50-61.

18. Farhoudi B, Alipour A, Ghodrati S, Seyedalinaghi S, Zanganeh M, Mohraz M. Barriers to adherence to antiretroviral treatment among inmates of a prison in Tehran, Iran: A qualitative study. Archives of Clinical Infectious Diseases. 2018;13(2).

19. Rodrguez-Daz CE, Rivera-Negrn RM, Clatts MC, Myers JJ. Health Care Practices and Associated Service Needs in a Sample of HIV-Positive Incarcerated Men in Puerto Rico: Implications for Retention in Care. Journal of the International Association of Providers of AIDS Care (JIAPAC). 2014;13(6):492-6.

20. Seyed Alinaghi SA, Farhoudi B, Mohraz M, Alipour A, Golrokhy R, Hosseini M, et al. Adherence to Antiretroviral Therapy and Tuberculosis Treatment in a Prison of Tehran, Iran. Infectious disorders drug targets. 2016;16(3):199-203. 
21. Altice FL, Mostashari F, Friedland GH. Trust and the acceptance of and adherence to antiretroviral therapy. Journal of Acquired Immune Deficiency Syndromes: JAIDS. 2001;28(1):47-58.

22. Soto Blanco JM, Perez IR, March JC. Adherence to antiretroviral therapy among HIV-infected prison inmates (Spain). International journal of STD \& AIDS. 2005;16(2):133-8.

23. Shalihu N, Pretorius L, van Dyk A, Vander Stoep A, Hagopian A. Namibian prisoners describe barriers to HIV antiretroviral therapy adherence. AIDS care. 2014;26(8):968-75.

24. White BL, Wohl DA, Hays RD, Golin CE, Liu H, Kiziah CN, et al. A pilot study of health beliefs and attitudes concerning measures of antiretroviral adherence among prisoners receiving directly observed antiretroviral therapy. AIDS Patient Care \& STDs. 2006;20(6):408-17.

25. Chakrapani V, Kamei R, Kipgen H, Kh JK. Access to harm reduction and HIV-related treatment services inside Indian prisons: Experiences of formerly incarcerated injecting drug users. International journal of prisoner health. 2013;9(2):82-91.

26. Todrys KW, Amon JJ, Malembeka G, Clayton M. Imprisoned and imperiled: access to HIV and TB prevention and treatment, and denial of human rights, in Zambian prisons. Journal of the International AIDS Society. 2011;14:8.

27. Kibret GD, Ferede A, Leshargie CT, Wagnew F, Ketema DB, Alebel A. Trends and spatial distributions of HIV prevalence in Ethiopia. Infectious Diseases of Poverty. 2019;8(1).

28. Fuge TG, Ayanto SY. Prevalence of smear positive pulmonary tuberculosis and associated risk factors among prisoners in Hadiya Zone prison, Southern Ethiopia Infectious Diseases. BMC Research Notes. 2016;9(1).

29. Terefe Gone F, George T, Emma RM. Factors influencing early antiretroviral therapy initiation amongst HIV-infected prisoners: a qualitative exploration in South Ethiopia. Preprint at https://doi.org/10.21203/rs.3.rs-223094/v1. 2021.

30. Cleary $M$, Horsfall J, Hayter M. Data collection and sampling in qualitative research: does size matter? Journal of Advanced Nursing. 2014;70(3):473-5.

31. Moen K, Middelthon A-L. Qualitative Research Methods. In: Laake P, Benestad HB, Olsen BR, editors. Research in Medical and Biological Sciences (Second Edition). Amsterdam: Academic Press; 2015. p. 321-78.

32. Gill P, Stewart K, Treasure E, Chadwick B. Methods of data collection in qualitative research: interviews and focus groups. BDJ. 2008;204(6):291.

33. Giorgi A. The Descriptive Phenomenological Psychological Method. Journal of Phenomenological Psychology. 2012;43(1):3-12.

34. Paley J. Phenomenology as qualitative research: a critical analysis of meaning attribution: London, England, New York, New York : Routledge; 2017.

35. QSR International. NVivo qualitative data analysis software. 12 ed. Doncaster, Australia: QSR International Pty Ltd;; 2018. 
36. Maxwell J. Designing a qualitative study. In: Bickman L, Rog D. J, editors. The SAGE handbook of applied social research methods. 41. 3rd ed. ed. Thousand Oaks: Thousand Oaks: SAGE Publications; 2009. p. 214-53.

37. Fazel S, Baillargeon J. The health of prisoners. The Lancet. 2011;377(9769):956-65.

38. WHO. Prisons and Health. World Health Organization (WHO), Regional office for Europe; 2014.

39. UNDOC. HIV prevention, treatment and care in prisons and other closed settings: a comprehensive package of interventions. Austria United Nations Office for Drugs and Crime (UNDOC); 2013.

40. Zaller N, Thurmond P, Rich JD. Limited spending: An analysis of correctional expenditures on antiretrovirals for HIV-infected prisoners. Public Health Rep. 2007;122(1):49-54.

41. Telisinghe L, Hippner P, Churchyard GJ, Gresak G, Grant AD, Charalambous S, et al. Outcomes of onsite antiretroviral therapy provision in a South African correctional facility. International Journal of STD \& AIDS. 2016;27(13):1153-61.

42. Mpawa H, Kwekwesa A, Amberbir A, Garone D, Divala OH, Kawalazira G, et al. Virological outcomes of antiretroviral therapy in Zomba central prison, Malawi; a cross-sectional study. Journal of the International AIDS Society. 2017;20(1):21623.

43. Telisinghe L, Charalambous S, Topp SM, Herce ME, Hoffmann CJ, Barron P, et al. HIV and tuberculosis in prisons in sub-Saharan Africa. The Lancet. 2016;388(10050):1215-27.

44. Reid SE, Topp SM, Turnbull ER, Hatwiinda S, Harris JB, Maggard KR, et al. Tuberculosis and HIV control in sub-Saharan African prisons: "thinking outside the prison cell". The Journal of infectious diseases. 2012;205 Suppl 2(suppl 2):S265.

45. Emanuele P. Antiretroviral Treatment in Correctional Facilities. HIV Clinical Trials. 2005;6(1):25-37.

46. UNODC/WHO/UNAIDS. Policy brief: HIV testing and counselling in prisons and other closed settings. Austria2009.

47. Culbert G. Violence and the perceived risks of taking antiretroviral therapy in US jails and prisons. International journal of prisoner health. 2014;10(2):94-110.

48. Sprague C, Scanlon ML, Radhakrishnan B, Pantalone DW. The HIV Prison Paradox: Agency and HIVPositive Women's Experiences in Jail and Prison in Alabama. Qualitative Health Research. 2017;27(10):1427-44.

49. Zack B. HIV prevention: Behavioral interventions in correctional settings. Public Health Behind Bars; FRobert B Greifingerrom Prisons to Communities. New York, USA: Springer; 2007. p. 156-73.

50. Ketema AK. Assessment of adherence to highly active antiretroviral therapy and associated factors among people living with HIV at debrebrihan referral hospital and health center, northeast ethiopia: A cross-sectional study. HIV/AIDS - Research and Palliative Care. 2015;7:75-81.

51. Denison JA, Koole O, Tsui S, Menten J, Torpey K, van Praag E, et al. Incomplete adherence among treatment-experienced adults on antiretroviral therapy in Tanzania, Uganda and Zambia. AIDS (London, England). 2015;29(3):361-71. 
52. Dewing S, Mathews C, Lurie M, Kagee A, Padayachee T, Lombard C. Predictors of poor adherence among people on antiretroviral treatment in Cape Town, South Africa: a case-control study. AIDS care. 2015;27(3):342-9.

53. FMH. National Guidelines for HIV/AIDS and Nutrition in Ethiopia Addis Ababa The Federal Democratic Republic of Ethiopia Ministry of Health (FMH); 2008.

54. Lucas KD, Eckert V, Behrends CN, Wheeler C, MacGowan RJ, Mohle-Boetani JC. Evaluation of Routine HIV Opt-Out Screening and Continuum of Care Services Following Entry into Eight Prison Reception Centers--California, 2012. MMWR: Morbidity \& Mortality Weekly Report. 2016;65(7):178-81.

55. Meyer JP, Cepeda J, Taxman FS, Altice FL. Sex-Related Disparities in Criminal Justice and HIV Treatment Outcomes: A Retrospective Cohort Study of HIV-Infected Inmates. American journal of public health. 2015;105(9):1901-10.

56. Meyer JP, Cepeda J, Wu J, Trestman RL, Altice FL, Springer SA. Optimization of human immunodeficiency virus treatment during incarceration: Viral suppression at the prison gate. JAMA Internal Medicine. 2014;174(5):721-9.

57. Davies NE, Karstaedt AS. Antiretroviral outcomes in South African prisoners: a retrospective cohort analysis. PloS one. 2012;7(3):e33309. 